\title{
A cadeira de rodas infantil sob a perspectiva do design emocional e da ergonomia
}

\section{The children's wheelchair from the perspective of emotional design and ergonomics}

La silla de ruedas infantil bajo la perspectiva del diseño emocional y la ergonomía

Suélen Maiara dos Reis Nascimento ${ }^{1}$

Camila Dalsin ${ }^{2}$

Jacinta Sidegum Renner ${ }^{3}$

Claudia Schemes ${ }^{4}$

${ }^{1}$ Bacharel em Design pela Universidade Feevale (Novo Hamburgo, RS). E-mail: suelenmreis@gmail.com, Orcid: http://orcid.org/0000-0002-1394-2764

${ }^{2}$ Mestre em Diversidade Cultural e Inclusão Social e bacharel em Moda pela Universidade Feevale (Novo Hamburgo, RS). Bolsista PROSUC/CAPES. E-mail: cadalsin@hotmail.com, Orcid: http://orcid.org/0000-0003-2201-2558

${ }^{3}$ Doutora em Engenharia de Produção com ênfase em Ergonomia pela Universidade Federal do Rio Grande do Sul (UFRGS). Docente no Programa de Pós-Graduação em Diversidade Cultural e Inclusão Social da Universidade Feevale (Novo Hamburgo, RS). E-mail: jacinta@feevale.br, Orcid: http://orcid.org/0000-0002-9904-4710

${ }^{4}$ Doutora em História pela Pontifícia Universidade Católica do Rio Grande do Sul (PUCRS). Docente no Programa de Pós-Graduação em Processos e

Manifestações Culturais da Universidade Feevale (Novo Hamburgo, RS). E-mail: claudias@feevale.br, Orcid: http://orcid.org/0000-0001-8170-9684 
Resumo: Considerando a contribuição do design no desenvolvimento das Tecnologias Assistivas, propõe-se, neste artigo, analisar a cadeira de rodas infantil sob a perspectiva do design emocional e da ergonomia, partindo da percepção das crianças usuárias e de seus cuidadores. Em termos metodológicos, este estudo se caracteriza como uma pesquisa observacional descritiva, com análise de dados sob o paradigma qualitativo. Foi utilizada na fase exploratória a ferramenta de Design Macroergonômico que incorpora as demandas dos usuários em todas as fases do processo. Embora os resultados apresentados nas entrevistas tenham apontado para a necessidade de alterações relacionadas à segurança da cadeira de rodas, verificou-se que as crianças usuárias identificaram os aspectos estéticos como fatores relevantes passíveis de mudança.

Palavras-chave: cadeira de rodas; criança com deficiência; design emocional; ergonomia.

\begin{abstract}
Considering the contribution of design in the development of Assistive Technologies, it is proposed, in this article, to analyze the child wheelchair from the perspective of emotional design and ergonomics, starting from the perception of the children users and their caregivers. In methodological terms, this study is characterized as a descriptive observational research, with data analysis under the qualitative paradigm. It was used in the exploratory phase the Macroergonomic Design tool that incorporates the demands of the users in all phases of the process. Although the results presented in the interviews pointed to the need for changes related to the safety of the wheelchair, it was verified that the child users identified the aesthetic aspects as a relevant factor that could change.
\end{abstract}

Keywords: wheelchair; children with disabilities; emotional design; ergonomics.

Resumen: Considerando la contribución del diseño en el desarrollo de las Tecnologías Asistivas, se propone en este artículo analizar la silla de ruedas infantil desde la perspectiva del diseño emocional y de la ergonomía, partiendo de la percepción de los niños usuarios y de sus cuidadores. En términos metodológicos, este estudio se caracteriza como una investigación observacional descriptiva, con análisis de datos bajo el paradigma cualitativo. Se utilizó en la fase exploratoria la herramienta de Diseño Macroergónico que incorpora las demandas de los usuarios en todas las fases del proceso. Aunque los resultados presentados en las entrevistas he apuntado a la necesidad de cambios relacionados con la seguridad de la silla de ruedas, se verificó que los niños usuarios identificaron los aspectos estéticos como factor relevante pasible de cambio.

Palabras clave: silla de ruedas; niños con discapacidad; diseño emocional; ergonomía. 


\section{INTRODUÇÃO}

Ao longo das últimas décadas, o percentual das pessoas com deficiência aumentou. Atualmente, existem no Brasil aproximadamente 45,6 milhões de pessoas com deficiência, representando 23,9\% da população total. Apesar da proporção de indivíduos com pelo menos uma deficiência ser maior entre adultos e idosos, seja ela visual, seja ela auditiva, motora ou mental/intelectual, percebe-se um crescimento relevante na percentagem do público infantil na faixa etária de 0 a 14 anos, totalizando 3.459.401 crianças (7,5\%).

Dependendo do grau de mobilidade do indivíduo, verifica-se a necessidade do uso de algum tipo de Tecnologia Assistiva (TA), que pode ser definida como qualquer instrumento ou processo que tenha como objetivo proporcionar uma maior autonomia, independência, qualidade de vida e inclusão social para a pessoa com deficiência. Para a criança com deficiência motora, a cadeira de rodas coloca-se como uma extensão de seu corpo, pois permite exercer o direito de ir e vir, o que é uma atividade importante para a manutenção da autonomia e qualidade de vida, além de ser um meio de interação com o corpo social. Assim sendo, quanto melhor constituída essa tecnologia assistiva, melhor será a vivência positiva que a criança terá, de modo que tenderá a associá-la a sentimentos positivos, e não somente às limitações advindas da deficiência.

Por ser um produto que é utilizado cotidianamente na posição sentada durante longos períodos, é essencial que a cadeira de rodas também seja o mais confortável possível. Assim, os aspectos ergonômicos e de conforto são de extrema relevância. A ergonomia trata do estudo da adequação do trabalho ao homem, atuando em um campo multidisciplinar, focando na adaptação de produtos para diminuir ou solucionar problemas de saúde, sejam físicos e/ou mentais. Considera-se que a sua aplicação ainda na concepção de um produto assegura a qualidade e diminui as chances de erros e riscos.

Partindo do princípio de que a cadeira de rodas é de suma importância para a vida da criança com deficiência motora, este artigo foi norteado pela seguinte questão de pesquisa: 'Sob a perspectiva do design emocional e da ergonomia, é possível realizar uma análise acerca da cadeira de rodas 
infantil partindo da percepção das crianças usuárias e de seus cuidadores?'. O objetivo geral foi analisar a cadeira de rodas infantil sob a perspectiva do design emocional e da ergonomia, partindo da percepção das crianças usuárias e de seus cuidadores.

\section{MATERIAIS E MÉTODOS}

A presente pesquisa caracterizou-se como observacional descritiva, com análise de dados sob o paradigma qualitativo. O campo de estudo foi o Centro Integrado de Especialidades em Saúde (CIES), localizado nas dependências de uma universidade do Rio Grande do Sul, onde são realizados atendimentos sem convênios e particulares, voltados a crianças e adultos nas áreas de Fisioterapia, Quiropraxia, Nutrição e Assistência Social.

O estudo foi realizado por um grupo composto de cinco crianças usuárias de cadeira de rodas, sendo que, destas, três responderam elas mesmas a pesquisa e duas tiveram a pesquisa respondida por seus cuidadores. Entre as crianças, quatro já nasceram com deficiência por complicações no parto, e uma ficou paraplégica após um atropelamento, quando tinha dois anos de idade. Das cinco crianças, duas tinham a cadeira de rodas com adaptações. Todas as crianças entrevistadas estudam em escolas municipais ou estaduais, em classes regulares. Salienta-se que se aplicaram tanto os questionários quanto a entrevista com os cuidadores, quando as crianças não conseguiam se comunicar em função da deficiência ter afetado sua oralidade. Também, essa foi a justificativa apresentada para o grupo de colaboradores ser constituído por poucas crianças.

Foi utilizada na fase exploratória a ferramenta de Design Macroergonômico (DM) proposta por Fogliatto e Guimarães (1999). Inicialmente, foi realizada uma entrevista não estruturada com as crianças e/ ou cuidadores. Nesta técnica, são feitas perguntas abertas para que se possa ter uma exploração mais ampla da coleta de dados em questão (PRODANOV; FREITAS, 2013). As entrevistas prévias à aplicação do questionário foram gravadas com a devida autorização dos cuidadores.

Esta pesquisa está inserida em um projeto de âmbito maior, intitulado "Desenvolvimento de produtos e adaptações ergonômicas para cadeira de 
rodas", aprovado pelo Comitê de Ética em Pesquisa (CEP) da universidade em questão, sob o registro de número 49410815.2.0000.5348. Em 2014, ele foi inscrito no Programa Pesquisador Gaúcho, da Fundação de Amparo à Pesquisa do Estado do Rio Grande do Sul (FAPERGS), sendo aprovado e contemplado com fomento para a execução da pesquisa. Possui parceria com a Associação de Lesados Medulares do Rio Grande do Sul (LEME), localizada em Novo Hamburgo, RS, e o Grupo Herval, de Dois Irmãos, RS.

Para a realização desta entrevista, foram elaboradas perguntas simples, com o intuito de que o público infantil participante compreendesse os questionamentos da forma mais clara possível. Partindo dos resultados da entrevista aberta, as respostas foram agrupadas de acordo com categorias preestabelecidas. Esse agrupamento por categorias foi a base para a criação de um questionário de investigação da satisfação dos usuários quanto às problemáticas encontradas na primeira entrevista.

Os questionários desenvolvidos utilizaram uma escala análogo-visual de 15 centímetros, com duas extremidades (ex.: insatisfeito - satisfeito / ruim - muito bom / inadequado - adequado), atribuindo, assim, um valor a cada item demandado. Nesse caso, o entrevistado deveria marcar um ' $x$ ' na linha conforme a sua percepção sobre o que está sendo questionado.

Especificamente nesse caso, foram utilizados, respectivamente, nos polos negativo e positivos, os termos 'ruim' e bom' para facilitar o entendimento das crianças. As marcações foram medidas na linha com o auxílio de uma régua, para depois efetuar-se uma média aritmética, sendo que os resultados foram apresentados em formato de gráficos.

Os gráficos foram apresentados neste artigo como forma meramente ilustrativa para facilitar a visualização dos itens questionados como prioridade de demanda. A opinião dos entrevistados é de alta relevância, posto que as alternativas de melhorias se dão com base nas necessidades do usuário, encontradas durante a coleta de dados.

\section{RESULTADOS DAS ENTREVISTAS E AVALIAÇÃO DOS CONSTRUCTOS}

Foram organizados quatro constructos a partir das respostas das entrevistas e posterior aplicação do questionário, sendo esses: aspectos 
de conforto; segurança; aspectos estéticos e aspectos lúdicos. O resultado desse questionário é apresentado em gráficos divididos por construtos e sua análise deu-se através do processo de triangulação a partir das falas das crianças e/ou cuidadores, dos autores de referência e da opinião das pesquisadoras.

\subsection{Aspectos do conforto}

No constructo A (Figura 1), foram abordados os aspectos relacionados ao conforto da cadeira de rodas infantil, em que se apresentaram quatro itens para a análise de satisfação do conforto: assento, encosto, apoio de pés e o que diz respeito ao ato de empurrar.


Fonte: Elaborada pelas autoras (2019).

Os resultados dos aspectos desse constructo foram positivos (maiores que 7,5 ), sendo alguns muito próximos do valor máximo. Pesquisas semeIhantes foram feitas com adultos que utilizam a cadeira de rodas, como a de Basso (2013), em que o conforto mostrava-se com resultados inferiores a 7,5 em seis dos sete aspectos de conforto expostos aos questionados. Diferentemente desses resultados, esses mesmos aspectos, quando apre- 
sentados às crianças, foram avaliados de forma mais positiva. Supõe-se que esse resultado se dá pelo fato de as crianças serem muito mais ativas e inquietas, o que as leva à maior movimentação do corpo em relação aos adultos, como é apresentado nas falas de dois cuidadores: "Ela [a criança] brinca de se esconder no pátio da escolinha. [...] ela não para um minuto" (Entrevistado 1). Ou, conforme o entrevistado 2 comenta: "Ela [a criança] participa de dança gaúcha".

$\mathrm{O}$ ato de brincar oportuniza à criança usuária de cadeira de rodas maior movimentação e, em consequência disso, menos desconforto pela posição estática sentada por tempo prolongado. Possivelmente isso contribua para que haja menos desconforto postural em comparação aos adultos usuários de cadeira de rodas, o que foi evidenciado nos resultados desta pesquisa.

\subsection{Aspectos de segurança}

Durante a entrevista aberta, uma das questões expostas pelos cuidadores das crianças relacionava-se com a segurança ao utilizar a cadeira de rodas. Foi questionada no constructo B (Figura 2) a opinião sobre a segurança das travas e quanto à estabilidade da cadeira de rodas (firmeza).

Figura 2 - Segurança

Qual sua opinião sobre a segurança de sua cadeira de rodas?

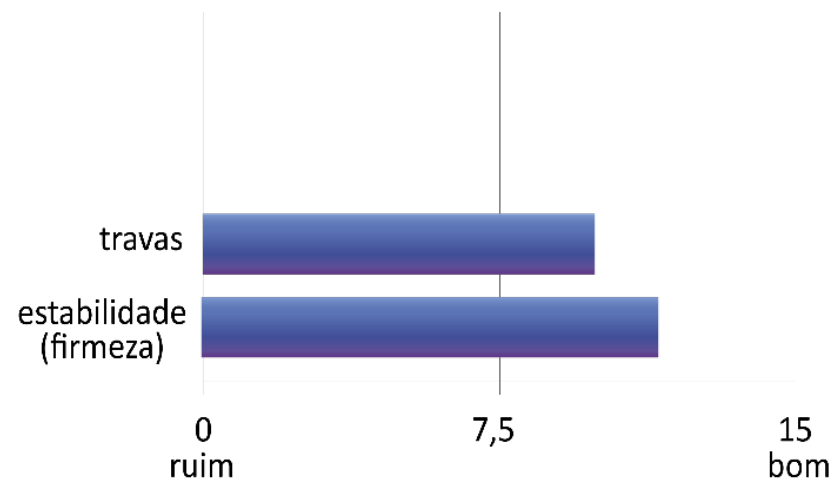

Fonte: Elaborada pelas autoras (2019). 
A preocupação com a segurança da criança decorre em função de um histórico de quedas, o que foi relatado da seguinte forma por um dos responsáveis: "Ela tava brincando na escola, a roda trancou e a cadeira virou" (Entrevistado 1). Também no âmbito escolar, verificou-se outro episódio de queda: "Ele caiu da cadeira mesmo com o cinto. O colega atravessou na frente e ele virou com a cadeira" (Entrevistado 3). Nesses casos, os cuidadores inquietam-se pela possibilidade de que a criança usuária de cadeira de rodas possa vir a se machucar em uma dessas quedas.

Outra preocupação refere-se à má qualidade das travas, que acabam quebrando devido ao tempo de uso, e à facilidade de destravamento, deixando os cuidadores apreensivos por não conseguirem controlar a criança usuária de cadeira de rodas, como citado na fala pelo entrevistado 3: "Elas [as travas] podem estar travadas, ele destrava e anda igual".

Mesmo com todos os aspectos apontados nesse constructo, os itens apresentam valores acima de 7,5. Segundo Norman (2008), os seres humanos projetam nos produtos suas emoções e a avaliação de algo bom ou ruim pode estar extremamente ligada às experiências pessoais de cada pessoa. Pressupõe-se então que, por mais que os cuidadores tenham a preocupação com a criança quanto à sua estabilidade e à utilização das travas da cadeira, para as crianças isso não é um problema, pois percebeu-se que, para elas, a cadeira de rodas é o meio de condução para que possam brincar, por exemplo.

\subsection{Aspectos estéticos}

No constructo C (Figura 3), relacionado aos aspectos estéticos da cadeira de rodas infantil, foi questionada a opinião das crianças quanto ao conforto do encosto e o funcionamento das rodas. 
Figura 3 - Aspectos estéticos

Qual sua opinião sobre a estética (beleza) de sua cadeira de rodas?

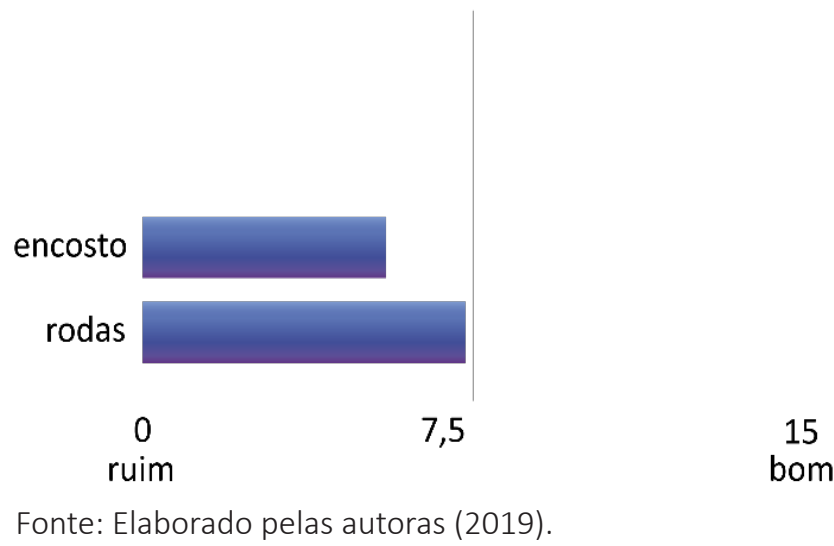

Embora na entrevista aberta as cores tenham sido citadas como satisfatórias, conforme se identifica na fala do entrevistado 3 - "A cor [da cadeira de rodas] foi ele que escolheu, ele é gremista, ama azul" -, outros aspectos foram indicados como passíveis de modificação para que a cadeira de rodas fique mais bonita, como se percebe no discurso da criança identificada como a entrevistada 5: "Acho que um design diferente nas rodas seria legal". Há uma grande dificuldade de se encontrar uma cadeira que seja apropriada ergonomicamente e esteticamente. Geralmente, são necessárias modificações e adaptações para que se ajuste melhor às necessidades da pessoa que a utiliza (MATTOS, 2017). Porém o porcentual da população de pessoas com deficiência que têm acesso a uma cadeira adequadamente ajustada é menor que 5\% (ORGANIZAÇÃO MUNDIAL DA SAÚDE [OMS], 2011).

Os resultados foram negativos (menor que 7,5 ) para os dois itens apresentados nesse constructo. Algumas falas mostram o interesse de que o espaço disponível na cadeira de rodas seja utilizado de uma forma melhor, como relatado pelo entrevistado 2: "Tem um amigo meu que faz grafite, ela quer que eu peça pra ele grafitar a cadeira dela". A aparência da cadeira de rodas interfere na forma como a pessoa com deficiência vai 
ser vista e interpretada (MATTOS, 2017). Nesse sentido, pode-se dizer que, atualmente, a cadeira de rodas infantil tem poucas variações estéticas em comparação com aquelas utilizadas por adultos. Algumas empresas dispõem de cadeiras de rodas coloridas, que é o único diferencial em relação às usadas por adultos.

Embora existam empresas que produzam cadeiras personalizadas com as temáticas de super-heróis ou desenhos animados, estas são vendidas a preços altos e a maioria das famílias de crianças cadeirantes entrevistadas não conseguiria custear esses adereços, em função da sua condição social. Outra questão relevante quanto à imagem que a cadeira de rodas pode transmitir é a de "coitadismo". Isso foi expresso por uma das crianças (entrevistada 4) da seguinte forma: "Elas me olham como se eu fosse coitadinha".

Nessa fala, pode-se perceber o descontentamento da criança com o julgamento preconceituoso de outras pessoas. Norman (2008) cita que, quanto mais experiências se têm com o objeto, maior será sua afetividade, seja ela positiva ou negativa. Mattos (2017), por sua vez, pontua que a estética da cadeira de rodas está extremamente ligada à percepção que as pessoas não deficientes têm da pessoa com deficiência. Segundo o autor, "objetos cujos materiais, formas e desenhos são antigos, escuros, desgastados e de aspecto frágil, por exemplo, são aparentemente associados a usuários idosos, doentes, frágeis [e] infelizes".

\subsection{Aspectos lúdicos}

Na Figura 4, são apresentados os resultados do constructo D sobre os aspectos lúdicos da cadeira de rodas. Ao longo das entrevistas e dos questionários, percebe-se a alegria das crianças com deficiência, expondo, assim, um resultado positivo no que diz respeito à ludicidade da cadeira de rodas. 
Figura 4 - Ludicidade



Fonte: Elaborada pelas autoras (2019).

Os resultados positivos (maiores que 7,5 ) indicaram a satisfação dos usuários nos aspectos lúdicos apresentados. Isso foi expresso na fala que se segue: "Sabia que a gente faz educação física? É cada dia uma educação física diferente" (Entrevistado 5). Ainda, de acordo com outra expressão oriunda da fala de uma avó (entrevistado 1): "Ela sempre diz: a cadeira de rodas são minhas pernas". O discurso da avó denota o quão importante é a cadeira de rodas na vida da criança com deficiência motora. Assim sendo, pressupõe-se que esta tecnologia assistiva torna-se parte do corpo da criança. Segue outra fala notável: "A cadeira de rodas é um meio de eu fazer tudo que eu quero" (Entrevistado 4). Nessa expressão, percebe-se o peso que a cadeira de rodas tem e tudo que ela representa na vida da criança com deficiência. Nesse sentido, fica evidente que este equipamento é parte fundamental da construção da criança como indivíduo apto para viver em sociedade (MENEZES; SANTOS, 2001).

Ao mesmo tempo que o uso da cadeira facilita a vida da criança, também evidencia a deficiência. Tal situação pode resultar em bullying, desrespeito e discriminação, pois ainda se faz uma associação da deficiência com características negativas (OMS, 2011). Outro fato importante é a tendência à naturalização dos cuidadores perante essas práticas. Muitos acreditam ser algo normal e sem saída, isso pelo paradigma cultural que se tem a séculos, de que atos como esses são "coisa de criança" e não devem 
ser levados a sério (FANTE, 2005) - embora esse pensamento venha mudando nas últimas décadas pela intervenção da escola e de pais com mais informação sobre o assunto.

Para amenizar essa situação do "ser diferente" no contexto infantil, os aspectos lúdicos podem harmonizar mais as relações. Menezes e Santos (2001) argumentam que a ludicidade é extremamente necessária, pois constrói na criança um caráter autônomo, torna-a mais hábil, sensível e compreensível.

\section{DISCUSSÃO}

Por fazer parte da condição humana, a deficiência será vivida permanentemente ou temporariamente por uma parte da população em alguma fase da sua vida (OMS, 2011). De acordo com a Secretaria de Direitos Humanos (BRASIL, 2017, p. 21), uma pessoa com deficiência é aquela que tem "impedimentos de longo prazo de natureza física, mental, intelectual ou sensorial, os quais, em interação com diversas barreiras, podem obstruir sua participação plena e efetiva na sociedade em igualdades de condições com as demais pessoas".

No Brasil, esse número representa aproximadamente 45,6 milhões de pessoas, isto é, 23,9\% da população (OLIVEIRA, 2012). Ainda que a proporção de pessoas com pelo menos uma deficiência seja maior entre adultos e idosos, constata-se um crescimento significativo no percentual de crianças na faixa etária de 0 a 14 anos, totalizando 7,5\% (INSTITUTO BRASILEIRO DE GEOGRAFIA E ESTATÍSTICA [IBGE], 2010), sendo que, destas, 2,39\% referem possuir alguma debilidade severa (OLIVEIRA, 2012). Em se tratando da deficiência motora, ela ocupa o terceiro lugar de maior prevalência neste público, abrangendo cerca de 1\% (IBGE, 2010).

Sendo a mobilidade uma atividade fundamental para a manutenção da qualidade de vida (DALSIN et al., 2019), verifica-se a necessidade do uso de produtos auxiliares para que a criança com deficiência possa obter maior autonomia e independência. Essa ajuda técnica é conhecida como Tecnologia Assistiva (TA), que proporciona maior autonomia, independência, qualidade de vida e inclusão social para a pessoa com deficiência (GALVÃO FILHO; DAMASCENO, 2006). 
Dependendo do grau de limitação na mobilidade do indivíduo, é preciso utilizar a cadeira de rodas. Entretanto apenas cerca de 10\% dos indivíduos com alguma incapacidade de movimentação utilizam esta como principal meio de auxílio na sua movimentação, pois, além de proporcionar o ato de ir e vir, ela imbrica outros benefícios, tais como a melhora na saúde, maior independência, autoestima e autoconfiança (OMS, 2011).

Sendo assim, verifica-se a existência de obstáculos na aquisição de uma cadeira de rodas que atenda totalmente tanto aos termos ergonômicos como aos estéticos. De acordo com a OMS (2011, p. 5), "para muitas pessoas, uma cadeira de rodas apropriada, bem projetada e adequada pode ser o primeiro passo para a inclusão e participação na sociedade". Embora se façam necessárias modificações e adaptações para que a cadeira de rodas se ajuste às necessidades da pessoa que a utiliza (MATTOS, 2017), o percentual da população que tem acesso a uma cadeira adequadamente ajustada é menor que 5\% (OMS, 2011).

Visando assegurar a mobilidade pessoal efetiva do público infantil com deficiência motora, deve-se aplicar os requisitos ergonômicos em todo o processo do projeto de design da cadeira de rodas, acarretando aumento do conforto, diminuição significativa dos riscos de erros e satisfação do indivíduo. Denominada também de fatores humanos, a ergonomia trata do estudo da adaptação do trabalho ao homem (IIDA; GUIMARÃES, 2016), objetivando "intervenções e projetos que visem melhorar, de forma integrada e não dissociada, a segurança, o conforto, o bem-estar e a eficácia das atividades humanas" (ASSOCIAÇÃO BRASILEIRA DE ERGONOMIA [ABERGO], s.d., p. 2).

De acordo com Ferro (2017), é essencial que a ergonomia integre todo o processo do projeto de design, desde a ideia até a concepção. A opinião e percepção do usuário são de suma relevância para o design ergonômico, assim como a utilização dos conhecimentos de ergonomia no projeto. Para Paschoarelli e Menezes (2009), o design ergonômico é definido com a aplicação de conhecimentos ergonômicos no desenvolvimento de produtos, buscando gerar peças e sistemas que contenham segurança, sejam confortáveis, eficientes, funcionais e práticos. Estudos como os de Almada (2012) e Ferro (2017) mostram a importância da utilização de aspectos 
macroergonômicos na geração e/ou adaptação de produtos voltados a pessoas com deficiência motora. Ambos os trabalhos visam ao aumento da qualidade de vida do usuário de cadeira de rodas e, consequentemente, têm grande relevância social.

Segundo Monge (2003), o maior desafio para a projeção de um bom e efetivo design universal é conseguir entender a relação da pessoa com o produto, deixando de observá-los somente como utilizadores dele. Diante disso, supõe-se que seja essencial a aplicação dos princípios do design universal juntamente do design emocional na projeção de dispositivos voltados para o público com deficiência motora, incluindo a cadeira de rodas, afinal, entende-se que este pode vir a contribuir para diminuir as diferenças entre as pessoas, de modo fácil, seguro e autônomo (HEIDRICH et al., 2006).

Um produto deve conseguir transmitir emoções, valores e a identidade do usuário para que seja completamente satisfatório. As interações humanas são permeadas por emoções, auxiliando no julgamento de um contexto em positivo ou negativo. Conforme Norman (2008, p. 38-9), as emoções interferem na tomada de decisões, na qual "emoções positivas são tão importantes quanto as negativas". Assim sendo, é impossível separar os produtos das nossas emoções, posto que os produtos não são neutros, interferindo nos nossos sentimentos (DAMÁSIO, 2000; DESMET; HEKKERT, 2002).

A avaliação de algo bom ou ruim pode estar extremamente ligada às experiências pessoais de cada pessoa. Um produto pode parecer desconfortável num quesito geral se este lhe causa constrangimento ou traz lembranças de algum momento ruim. Por outro lado, pode parecer mais confortável se sua estética for agradável ou seu uso for facilitado (NORMAN, 2008). No design, a estética, a funcionalidade e a usabilidade são a principal intenção quando se faz um projeto. Por vezes, o aspecto emocional que o produto poderá causar ao usuário é esquecido, mesmo sendo ele de suma importância na interação da pessoa com o produto (MONT'ALVÃO; DAMAZIO, 2008).

Norman (2008) divide o design emocional em três níveis: visceral, comportamental e reflexivo. Segundo o autor, o nível visceral é a primeira percepção que se tem do produto e está interligado ao aspecto físico; o nível 
comportamental é a percepção que se tem após o uso do produto, tendo como prioridade a função, não importando mais a estética, e sim a prioridade da necessidade do usuário; e o nível reflexivo, que está relacionado às sensações que o produto evoca no usuário, seja ele por lembranças, seja ele por experiências ou pela preocupação com autoimagem, por exemplo. É necessário atingir os três níveis para que um produto seja bem-sucedido.

Embora o ser humano tenha tendência de instintivamente relacionar emoção com beleza através da construção de objetos atrativos visualmente, evidencia-se que o produto também deve apresentar funcionalidade e aplicação de conceitos de ergonomia, além de um preço apropriado e acessível (DALSIN et al., 2019). Norman (2008) comenta que a beleza, a diversão e o prazer produzem o sentimento de alegria, essencial para a curiosidade das pessoas e para o aprendizado, beneficiando na lida com o estresse. O lúdico, por sua vez, está muito presente nos produtos direcionados ao público infantil.

A definição de lúdico é, segundo Menezes e Santos (2001, p. 4), a "qualidade daquilo que estimula através da fantasia, do divertimento ou da brincadeira". Massa (2015) considera que a ludicidade é um sentimento, junção de ação, emoção e pensamento, e que o indivíduo se constitui através da vivência da ludicidade. Silva (2016) e Loro (2015) enfatizam a importância do ato de brincar no desenvolvimento da criança, fazendo com que o público infantil com deficiência tenha uma maior participação junto ao corpo social.

Oriundo desta contextualização, o processo de inclusão social mostra-se imprescindível. Sassaki (2010, p. 39) descreve-a como o "processo pelo qual a sociedade se adapta para poder incluir, em seus sistemas sociais gerais, pessoas com deficiência (além de outras) e, simultaneamente, essas se preparam para assumir seus papéis na sociedade". Ainda, conforme a autora, cabe às pessoas, enquanto sociedade, buscar exclusão de barreiras que impeçam as pessoas com deficiência de terem acesso a todos os meios, físicos ou sociais, que ajudem no seu desenvolvimento. Logo, o design emocional e a ergonomia aplicados na cadeira de rodas podem vir a ser mediadores neste processo. 
Diante da análise dos resultados dos questionários, juntamente dos discursos obtidos durante as entrevistas, foi possível observar alguns aspectos com maior necessidade de interferência, embora estes não tenham se tornado relevantes nos gráficos por serem bem específicos de cada criança. Salienta-se que os gráficos são representativos de uma amostra pequena, por este motivo, dá-se maior ênfase aos resultados qualitativos expressos verbalmente pelas crianças ou responsáveis. Portanto seria necessário aplicar o questionário com um maior número de crianças, para uma avalição mais abrangente e aprofundada dos problemas relacionados à cadeira de rodas infantil.

Quanto aos resultados dos constructos, destacam-se os resultados do constructo $D$, relacionado à estética, que apresentou maior necessidade de interferência. Ambos os aspectos apresentados nesse constructo tiveram resultados negativos, sendo o encosto avaliado como a maior demanda para mudança.

É relevante frisar a importância de se chegar a uma solução que não exclua as crianças que não possuam condições financeiras de adquirir um produto ou serviço de custo elevado. Dessa forma, a solução de um projeto deve atender aos requisitos referentes à estética do encosto e da ergonomia, bem como ser de fácil aquisição pela maior quantidade de pessoas possíveis.

\section{CONSIDERAÇÕES FINAIS}

As respostas dadas nas entrevistas serviram de base para a elaboração do questionário, mas, além disso, pontos relevantes para a pesquisa foram citados nas entrevistas. No caso dos aspectos estéticos, embora difícil de mensurar a partir dos gostos pessoais de cada criança, a ferramenta do Design Macroergonômico (DM) permitiu avaliar a estética percebida pelos usuários.

A aplicação do lúdico na cadeira de rodas pode apresentar-se como um aspecto relevante para maior conforto e/ou inclusão social. Com a aplicação de personagens ou quaisquer outros desenhos no encosto, acrescidos ou não de texturas, é possível trazer novas experiências e sensações, gerando novas significações para a criança condicionada ao uso dessa tecnologia assistiva. 
Além da bibliografia em algumas áreas relacionadas a essa pesquisa ser escassa, principalmente quanto ao design emocional, houve algumas limitações durante o processo de coleta de dados. Conseguir horários para as entrevistas e os questionários foi dificultoso, visto que as crianças são atendidas no CIES com horários marcados e em poucos dias da semana. Outra dificuldade foi conseguir que as crianças se expressassem com naturalidade, pois muitas vezes ficavam retraídas e envergonhadas.

Considera-se que muito ainda pode ser feito para melhorias na cadeira de rodas infantil, considerando a escassez de projetos de design realmente satisfatórios e com a participação do usuário na percepção dos problemas relacionados à cadeira de rodas infantil.

\section{REFERÊNCIAS}

ASSOCIAÇÃO BRASILEIRA DE ERGONOMIA (ABERGO). O que é ergonomia. [s.d.]. Disponível em: http://www.abergo.org.br/internas.php?pg=o_que_e_ergonomia. Acesso em: 21 mar. 2019.

ALMADA, J. F. Disposição ergonômica para acomodação de pessoas com deficiência física em transporte coletivo. 2012. 169 f. Dissertação (Mestrado em Inclusão Social e Acessibilidade) - Feevale, Novo Hamburgo, RS, 2012. Disponível em: http://biblioteca.feevale.br/Dissertacao/DissertacaoJuanAlmada.pdf. Acesso em: 16 maio 2018.

BASSO, C. R. Parâmetros ergonômicos de conforto para usuários de cadeiras de rodas. 2013. 58 f. Monografia (Artigo de Conclusão do Curso de Design) - Feevale, Novo Hamburgo, RS, 2013. Disponível em: http://biblioteca.feevale.br/Artigo/ ArtigoClaudiaBasso.pdf. Acesso em: 29 ago. 2018.

BRASIL. Convenção sobre os Direitos das Pessoas com Deficiência: Lei Brasileira de Inclusão da Pessoa com Deficiência. Brasília: Secretaria de Direitos Humanos, 2017.

DALSIN, C.; HAUBERT, B.; RENNER, J. S.; SCHEMES, C. O design da cadeira de rodas infantil e o processo de exclusão/inclusão social: uma revisão integrativa da literatura. Revista Multitemas, Campo Grande, MS, v. 24, n. 56, p. 59-80, jan./ abr. 2019.

DAMÁSIO, A. O mistério da consciência: do corpo e das emoções do conhecimento de si. São Paulo: Companhia das Letras, 2000. 
DESMET, P. M. A.; HEKKERT, P. The basis of product emotions. In: GREEN, W.; JORDAN, P. (Coord.). Pleasure with products, beyond usability. London: Taylor \& Francis, 2002. p. 60-8.

FANTE, C. Fenômeno bullying: como prevenir a violência nas escolas e educar para a paz. São Paulo: Verus, 2005.

FERRO, B. H. Design ergonômico como ferramenta para a inclusão social: o caso dos usuários cadeirantes. 2017. 214 f. Dissertação (Mestrado em Diversidade Cultural e Inclusão Social) - Universidade Feevale, Novo Hamburgo, RS, 2017 Disponível em: http://biblioteca.feevale.br/Dissertacao/DissertacaoBrunaHFerro.pdf. Acesso em: 16 maio 2018.

FOGLIATTO, F. S.; GUIMARÃES, L. B. M. Design macroergonômico de postos de trabalho. Produto \& Produção, Porto Alegre, v. 3, n. 3, p. 1-15, 1999.

GALVÃO FILHO, T. A.; DAMASCENO, L. L. Tecnologias Assistivas para autonomia do aluno com necessidades educacionais especiais. Inclusão: Revista da Educação Especial, v. 1, n. 1, p. 25-33, 2006. Disponível em: http://atividadeparaeducacaoespecial. com/wp-content/uploads/2014/07/REVISTA-TECNOLOGIA-ASSISTIVA-E-NEE.pdf. Acesso em: 20 jun. 2018.

HEIDRICH, R.; TOROK, D. L.; CAPPELATTI, E.; SILVA, L. F.; MULLER, M. S.; MASOTTI, M. Design Inclusivo: desenvolvendo e utilizando tecnologias de informação e comunicação para alunos com necessidades educacionais especiais. Revista Renote, Porto Alegre, v. 4, n. 2, p. 1-10, dez. 2006. Disponível em: http://www.seer.ufrgs. br/renote/article/view/14189/8158. Acesso em: 22 mar. 2018.

IIDA, I.; GUIMARÃES, L. B. M. Ergonomia: projeto e produção. 3. ed. São Paulo: Edgard Blücher, 2016.

INSTITUTO BRASILEIRO DE GEOGRAFIA E ESTATÍSTICA (IBGE). Censo Demográfico 2010: características gerais da população, religião e pessoas com deficiência. Rio de Janeiro, 2010.

LORO, A. R. A importância do brincar na educação infantil. 2015. 42 f. Trabalho de Conclusão de Curso (Bacharel em Educação Física) - Universidade Regional do Noroeste do Estado do Rio Grande do Sul (UNIJUí), ljuí, RS, 2015. Disponível em: http://bibliodigital.unijui.edu.br:8080/xmlui/bitstream/handle/123456789/3391/ Aline\%20Loro\%20TCC\%20p\%C3\%B3s\%20banca.pdf?sequence=1. Acesso em: 12 abr. 2018. 
MASSA, M. S. Ludicidade: da etimologia da palavra à complexidade do conceito. Aprender: Caderno de Filosofia e Psicologia da Educação, Vitória da Conquista, BA, ano IX, n. 15, p. 111-30, 2015. Disponível em: http://periodicos.uesb.br/index.php/ aprender/article/viewFile/5485/pdf_39. Acesso em: 20 maio 2018.

MATTOS, L. M. Julgamento visual de cadeiras de rodas: contribuições para o design de produtos assistivos. Dissertação (Mestrado em Design) - Faculdade de Arquitetura, Artes e Comunicação, Universidade Estadual Paulista, Bauru, SP, 2017. Disponível em: https://repositorio.unesp.br/bitstream/handle/11449/152003/ mattos_Im_me_bauru.pdf?sequence=3\&isAllowed=y. Acesso em: 11 abr. 2018.

MENEZES, E. T.; SANTOS, T. H. Verbete lúdico. Dicionário Interativo da Educação Brasileira (Educabrasil). São Paulo: Midiamix, 2001. Disponível em: http://www. educabrasil.com.br/ludico/. Acesso em: 1o maio 2018.

MONGE, N. Design de produtos inclusivos, satisfatórios: a abordagem holística ao design inclusivo. Artigos Caleidoscópio, p. 117-34, 2003. Disponível em: http://recil. grupolusofona.pt/bitstream/handle/10437/2679/Design\%20de\%20Produtos\%20 Inclusivos\%20Satifat\%C3\%B3rios.pdf?sequence=1. Acesso em: 10 mar. 2018.

MONT'ALVÃO, C.; DAMAZIO, V. (Coord.). Design, ergonomia e emoção. Rio de Janeiro: Mauad, 2008.

NORMAN, D. Design emocional: por que adoramos (ou detestamos) os objetos do dia a dia. Rio de Janeiro: Rocco, 2008.

OLIVEIRA, L. M. B. Cartilha do Censo 2010: pessoas com deficiência. Secretaria de Direitos Humanos da Presidência da República (SDH/PR), Secretaria Nacional de Promoção dos Direitos da Pessoa com Deficiência (SNPD), Coordenação-Geral do Sistema de Informações sobre a Pessoa com Deficiência. Brasília: SDH-PR/SNPD, 2012.

ORGANIZAÇÃO MUNDIAL DA SAÚDE (OMS). Relatório mundial sobre a deficiência. São Paulo: SEDPCD, 2011. Disponível em: http://apps.who.int/iris/bitstream/ handle/10665/44575/9788564047020_por.pdf;jsessionid=96FC8FE45F9B214D5 7F4F148D9D225D8? sequence=4. Acesso em: 2 abr. 2018.

PASCHOARELLI, L. C.; MENEZES, M. S. M. (Org.). Design e ergonomia: aspectos tecnológicos. São Paulo: Editora UNESP, 2009. Disponível em: http://books.scielo. org/id/yjxnr 
PRODANOV, C. C.; FREITAS, E. C. Metodologia do trabalho científico: métodos e técnicas da pesquisa e do trabalho acadêmico. Novo Hamburgo, RS: Feevale, 2013.

SASSAKI, R. K. Inclusão: construindo uma sociedade para todos. 3. ed. Rio de Janeiro: WVA, 2010.

SILVA, M. G. A importância do brincar na Educação Infantil. 2016. 21 f. Trabalho de Conclusão de Curso (Licenciatura em Pedagogia a Distância) - Centro de Educação, Universidade Federal do Rio Grande do Norte, Natal, 2016. 